\title{
Rewiring of experimentally disturbed seed dispersal networks might lead to unexpected network configurations
}

\author{
José M. Costa ${ }^{\mathrm{a}, \mathrm{b}, *}$, Jaime A. Ramos ${ }^{\mathrm{b}}$, Luís P. da Silva ${ }^{\mathrm{a}, \mathrm{b}}$, Sérgio Timóteo ${ }^{\mathrm{a}}$, \\ Pedro Andrade ${ }^{c, d}$, Pedro M. Araújo ${ }^{\mathrm{b}}$, Camilo Carneiro ${ }^{\mathrm{e}, \mathrm{f}}$, Edna Correia ${ }^{\mathrm{g}}$, \\ Paulo Cortez ${ }^{\mathrm{h}}$, Marcial Felgueiras ${ }^{\mathrm{i}}$, Carlos Godinho ${ }^{\mathrm{j}}$, Ricardo Jorge Lopes ${ }^{\mathrm{c}}$, \\ Cláudia Matos ${ }^{\mathrm{k}}$, Ana Cláudia Norte ${ }^{\mathrm{b}}$, Pedro F. Pereira ${ }^{\mathrm{j}}$, António Rosa ${ }^{\mathrm{l}}$, \\ Ruben H. Heleno ${ }^{\mathrm{a}}$
}

\author{
${ }^{a}$ Centre for Functional Ecology, Department of Life Sciences, University of Coimbra, 3000-456 Coimbra, Portugal \\ ${ }^{\mathrm{b}}$ MARE - Marine and Environmental Sciences Centre, Department of Life Sciences, University of Coimbra, \\ 3000-456 Coimbra, Portugal \\ ${ }^{\mathrm{c}}$ CIBIO, Centro de Investigação em Biodiversidade e Recursos Genéticos, Universidade do Porto, InBIO, \\ Laboratório Associado, Universidade do Porto, Campus Agrário de Vairão, 4485-661, Vairão, Portugal \\ ${ }^{\mathrm{d}}$ Departamento de Biologia, Faculdade de Ciências, Universidade do Porto, 4169-007, Porto, Portugal \\ ${ }^{\mathrm{e}}$ Department of Biology \& CESAM, University of Aveiro, Campus de Santiago, 3810-193 Aveiro, Portugal \\ ${ }^{\mathrm{f}}$ South Iceland Research Centre, University of Iceland, Lindarbraut 4, IS-840 Laugarvatn, Iceland \\ ${ }^{\mathrm{g}}$ Centro de Estudos do Ambiente e do Mar (CESAM), Departamento de Biologia Animal, Faculdade de Ciências da \\ Universidade de Lisboa, 1749-016 Lisboa, Portugal \\ ${ }^{\mathrm{h}}$ Centro de Investigação de Montanha (CIMO), ESA, Instituto Politécnico de Bragança, Campus de Sta. Apolónia, \\ 5300-253 Bragança, Portugal \\ iA ROCHA, Apartado 41, 8501-903 Mexilhoeira Grande, Portugal \\ ${ }^{\mathrm{j}}$ Labor - Laboratório de Ornitologia, Instituto de Ciências Agrárias e Ambientais Mediterrânicas (ICAAM), \\ University of Évora, 7002-554 Évora, Portugal \\ ${ }^{\mathrm{k}}$ Grupo de Anilhagem do Litoral Alentejano, 7630-711, Bicos - Odemira, Portugal \\ ${ }^{1}$ Santarém, Portugal
}

Received 13 September 2017; accepted 19 May 2018

Available online 26 May 2018

\begin{abstract}
The consequences of species extinctions in ecological communities may be buffered through the rearrangement (rewiring) of the interactions between the remaining species. The structural and functional consequences of such extinctions can be explored by means of computer simulations that try to predict secondary extinctions and the degradation of ecosystem services. However, to improve the accuracy of these simulations, it is pivotal to evaluate their performance in predicting changes observed in natural communities. In this study, we first described the avian seed dispersal networks in 17 sites throughout Portugal, and found that blackberry (Rubus ulmifolius) was the most dispersed species in 13 out of the 17 sites. Second, we performed a manipulative experiment to evaluate the effect of removing the most dispersed plant species and compared the observed outcome in the structure of the network with computer simulations with and without rewiring. Observed changes were consistent with some rapid network rewiring, with dispersers shifting to alternative fruit species. Although the observed network topology after the
\end{abstract}

\footnotetext{
*Corresponding author at: Centre for Functional Ecology, Department of Life Sciences, University of Coimbra, 3000-456 Coimbra, Portugal.

E-mail address: jose.costa@student.uc.pt (J.M. Costa).
} 
experimental removal was not accurately predicted, the extinction simulation with rewiring performed considerably better than that without rewiring. Individual species roles were even harder to predict than emergent network properties on both types of models. We show that incorporating rewiring rules can considerably increase the accuracy of species extinction models, however, the functional consequences of losing important resources might not be easily anticipated, and rewiring might occur in unexpected directions.

(c) 2018 Gesellschaft für Ökologie. Published by Elsevier GmbH. All rights reserved.

Keywords: Ecological networks; Frugivory; Passerines; Rubus ulmifolius

\section{Introduction}

The loss of any species from a community entails a concomitant loss of all its interactions with other species, whether they are prey, predators, hosts, parasites or mutualists (Bond 1994). In some cases, the extinction of these ecological interactions can lead to secondary species extinctions (Brodie et al. 2014), which are intrinsically hard to predict (Ives \& Cardinale 2004; Brodie et al. 2014; Timóteo, Ramos, Vaughan, \& Memmott 2016) as communities may undergo a structural rearrangement through the establishment of new interactions among the remaining species, i.e. rewiring (Brosi \& Briggs 2013; Goldstein \& Zych 2016; Timóteo et al. 2016; CaraDonna et al. 2017; Hallett, Mitchell, Chamberlain, \& Karron 2017). Recently, the complex web of interactions that sustain long-term survival of co-occurring species has been visualised and analysed in the form of interaction networks, whose structure can be described by topological descriptors, such as connectance, nestedness, or specialization (Petanidou, Kallimanis, Tzanopoulos, Sgardelis, \& Pantis 2008; Ramos-Jiliberto, Valdovinos, Moisset de Espanés, \& Flores 2012; Poisot, Stouffer, \& Gravel 2014; Trøjelsgaard, Jordano, Carstensen, \& Olesen 2015).

Under the ongoing global biodiversity crisis, gaining predictive capacity regarding the consequences of species extinctions is arguably one of the most pressing needs in ecology (Isbell et al. 2017). Extinction simulations of species interaction networks can be particularly useful to predict consequences of species extinctions at the community level (Rumeu et al. 2017). Several studies have now shown that the extent of secondary extinctions is affected by the original structure of the networks, for example with more connected mutualistic communities being more robust to such perturbations (Thébault \& Fontaine 2010). However, such simulations have been increasingly criticised for being too conservative regarding the establishment of new interactions (Blüthgen, 2010; Vieira \& Almeida-Neto 2015). Although most studies to date do not allow network rewiring (i.e. the emergence of new interactions that compensate for lost ones) (Memmott, Waser, \& Price 2004; Santamaría, Galeano, Pastor, \& Méndez 2014; Correa et al. 2016), some began to incorporate different algorithms that allow some type of network rearrangement (Carvalheiro, Barbosa, \& Memmott 2008; Kaiser-Bunbury et al. 2010; Ramos-Jiliberto et al. 2012; Schleuning et al. 2016). To prevent the virtual creation of interactions that are actually impossible due to morphological, temporal or spatial mismatches, i.e. forbidden links (Jordano 2016), some of these studies constrain rewiring to previously observed interactions (e.g. KaiserBunbury et al. 2010; Timóteo et al. 2016). The incorporation of rewiring in extinction simulations showed ecological networks to be more robust to secondary extinctions than when no rewiring was accounted (Kaiser-Bunbury et al. 2010). Nevertheless, since the potential interactions considered in simulations with rewiring are often constrained by the locally observed interactions, these may be biased towards the most abundant interactions (Fründ, McCann, \& Williams 2016; Plein, Morris, Moir, \& Vesk 2017). Therefore, the potential of natural communities to originate new interactions that have not been previously recorded in the target network remains unclear, rendering most simulations highly speculative as they may not reflect the real consequences of species extinctions (Timóteo et al. 2016). To overcome this limitation and increasing the spectrum of potential interactions being established during rewiring simulations, one can incorporate information of interactions observed on other locations.

Given the ongoing threat that frugivores and their habitats are facing worldwide (Farwig \& Berens 2012), experiments on how seed dispersal networks behave after the extinction of fleshy-fruited plant species are needed to evaluate the potential consequences for the remaining species in these networks, which ultimately may affect plant recruitment and long-term vegetation dynamics (Traveset, Heleno, \& Nogales 2014; Bello et al. 2015; Rumeu et al. 2017). On the one hand, the typical generalist nature of frugivorous interactions (Fuentes 1995; Blüthgen, Menzel, Hovestadt, Fiala, \& Blüthgen 2007) is likely to render dispersal networks more robust to species extinctions than predicted through constrained extinction simulations that do not allow the establishment of previously unobserved interactions (Rumeu et al. 2017). On the other hand, there are important morphological, temporal, and spatial limitations to the interactions between fruits and their bird dispersers (Olesen et al. 2011), and unconstrained rewiring might lead to a dangerous overestimation of network resistance to secondary extinctions (Ramos-Jiliberto et al. 2012; Rumeu et al. 2017). Therefore, identifying potential interactions is essential for meaningful extinction simulations. 
There are four objectives to this study: (1) characterize the range of potential pairwise interactions between fruits and their avian dispersers during the peak of the fruiting season in Portugal; (2) identify the most important fleshyfruited plant species for birds during that period; (3) evaluate the structural plasticity of a seed dispersal network after the experimental removal of the most abundant fruit resource; (4) evaluate which in silico extinction simulations, with or without rewiring, provide better predictions of the observed network structure of a manipulated community. We predict that frugivorous birds, after the removal of the most important fruit resource, will start to disperse new seed species thus diverting their seed dispersal services to co-occurring plants, as well as increase the frequency of previously dispersed seed species.

\section{Materials and methods}

This work is divided in two parts. First, we compiled fruitfrugivorous bird interactions at a national scale to identify the most important fleshy-fruited plant species, their dispersers, and the potential interactions between the two groups (objectives 1 and 2). Second, we manipulated a seed dispersal network and compared the observed changes in the network's topology with those predicted by secondary extinction simulations with and without rewiring (objectives 3 and 4).

\section{Characterization of the seed dispersal networks}

We sampled 17 sites across mainland Portugal (Fig. 1) for five consecutive days in the first half of September 2012-2014. This period corresponds to the peak of abundance and richness of fleshy fruits and coincides with the passage of many migrant birds (Costa, da Silva, Ramos, \& Heleno 2016). At each site, approximately $100 \mathrm{~m}$ of mist nets were operated per day (with some small adjustments to comply with logistic constraints and bird safety) for five hours after dawn to capture birds. The nets were visited every 30 min and any bird captured was kept inside a cotton bag for up to $30 \mathrm{~min}$ to obtain a dropping (see Heleno, Olesen, Nogales, Vargas, \& Traveset 2013). Under a dissecting microscope, all undamaged seeds retrieved from bird droppings were counted and identified to the lowest taxonomical level possible by comparison with a comprehensive seed reference collection at the Centre for Functional Ecology of the University of Coimbra. We defined interaction frequency of a bird-plant pairwise interaction as the number of droppings of each bird species containing at least one intact seed from any plant species (i.e. frequency of occurrence) (see Vázquez, Morris, \& Jordano 2005; Heleno, Olesen et al. 2013; Correia, Timóteo, Rodríguez-Echeverría, Mazars-Simon, \& Heleno 2016). To assess the availability of fleshy fruits, we counted all ripe fruits along three linear transects, running parallel to the mist-nets at each site, each of them consisting of a rectangle of $2 \mathrm{~m} \times 25 \mathrm{~m}\left(50 \mathrm{~m}^{2}\right)$. Although we might have missed some rare fleshy-fruiting species at each site, they represent a very large sampling area $\left(150 \mathrm{~m}^{2}\right.$ per site), and they were considered representative of the local fruit availability by the observers.

\section{Experimental removal of the most dispersed plant species}

To experimentally evaluate the rewiring capacity of plant-frugivore interactions, we performed a manipulative experiment in which we manually removed all fruits of the most dispersed plant species (Rubus ulmifolius, hereafter blackberry, see results) from one site, and compared the composition and structure of the seed dispersal network before and after the removal.

This experiment was performed between the 1st and 14th of September 2015, in a secondary native woodland in central Portugal (site 18, Fig. 1) dominated by maritime pine (Pinus pinaster), Pyrenean oak (Quercus pyrenaica), and English oak (Q. robur), with an understory of strawberry tree (Arbutus unedo), hawthorn (Crataegus monogyna), and narrow-leaved mock privet (Phillyrea angustifolia). This site was selected due to the high local abundance of blackberry fruits (the overall most important fruit resource across the 17 sites), the large abundance of other fruit resources, and the concentrated distribution of blackberry fruits which made their removal logistically possible in a single afternoon. During seven consecutive days, we assessed seed dispersal interactions by retrieving seeds from the droppings of mist-netted birds. On the afternoon of the 7th day, we manually removed all ripe and unripe blackberries within a radius of $100 \mathrm{~m}$ from the mist nets. After that removal, we continued to sample in the same way for another seven consecutive days. Fruit availability was also estimated by counting all ripe standing fruits along a $2 \mathrm{~m} \times 75 \mathrm{~m}$ transect running parallel to the mistnets on day 5 (before) and day 10 (after the removal). The variation in the total number of captured birds and number of retrieved droppings (total, with seeds overall, with blackberry's seeds, and with seeds from other species), before and after the removal of blackberries, was assessed with G-tests.

\section{Secondary extinction simulations}

We evaluated the performance of secondary extinction simulations with and without rewiring, against the observed structure of the manipulated network. For these comparisons, the following descriptors were used: (1) weighted connectance, the ratio between the mean number of interactions per species and the total number of species in the network (Bersier, Banasek-Richter, \& Cattin 2002); (2) network specialization $\mathrm{H}_{2}{ }^{\prime}$, which measures the community level selectiveness of partners as a departure from a random (i.e. abundance-based) interaction pattern (Blüthgen, Menzel, \& Blüthgen 2006); (3) weighted nestedness metric based on Overlap and Decreasing Fill (WNODF; Almeida-Neto \& 

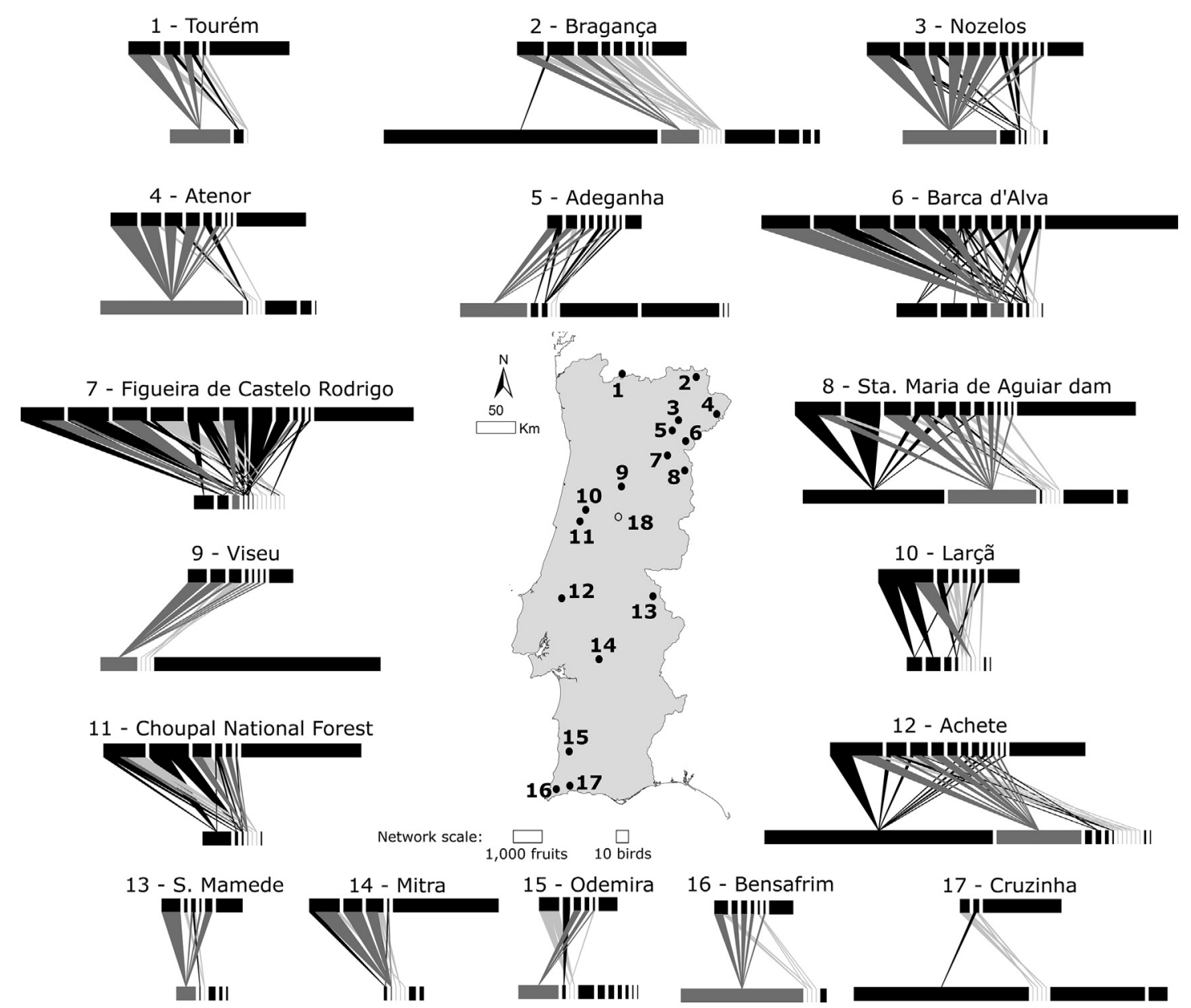

atili
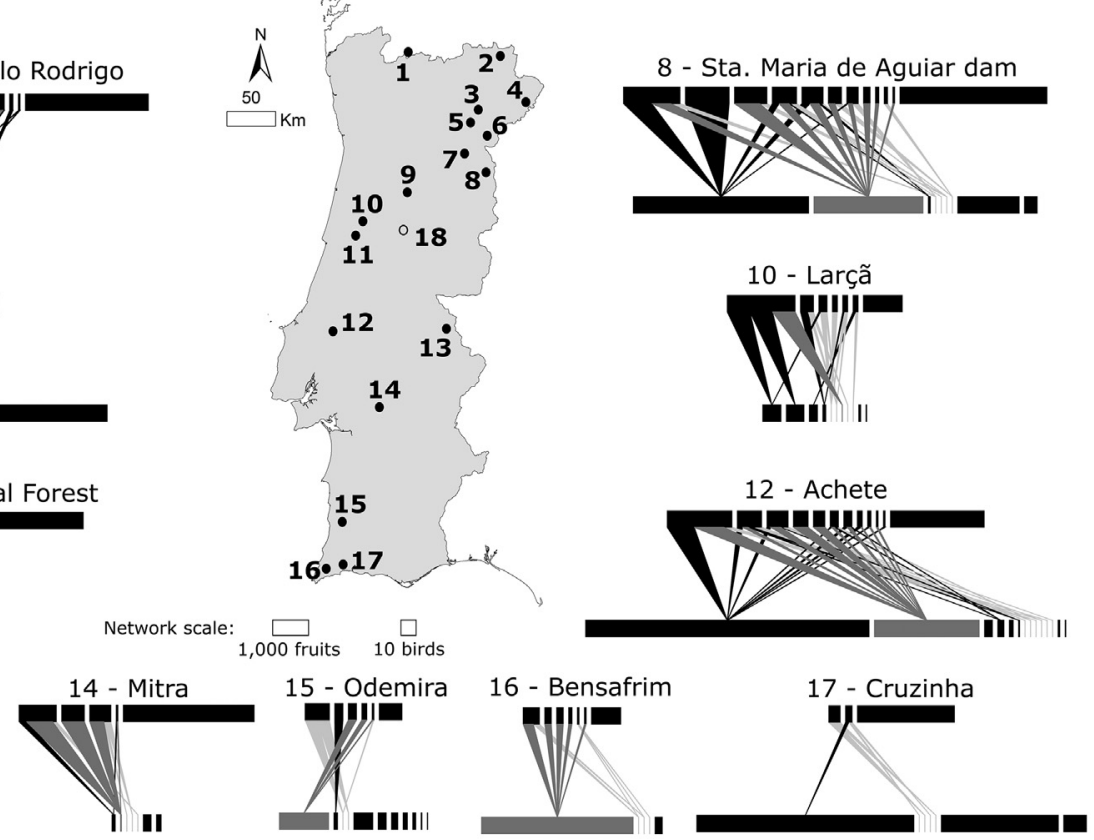

Fig 1. Location and structure of the 17 seed dispersal networks assembled in this study and drawn to the same scale. The experimental site where blackberries were removed corresponds to site 18 (open circle). In each network, the upper and lower levels represent bird and plant species, respectively, and the width of the links between the levels is proportional to the number of droppings of each bird species that contained intact seeds. The width of each bird's and plant's box depicts, respectively, the number of captured birds and the abundance of fruits in the transects. The bird boxes without any links include all captured bird species that did not disperse any seeds. Interactions with the blackberry are represented in dark grey; plants whose fruits were found in the transects are represented in black; and plants whose seeds were found in the droppings but not in the transects are represented in light grey.

Ulrich 2011), a measure of the nestedness of the network, quantifying to what degree interactions are organized around a core of highly generalist species; (4) bird species strength, a measure of the importance of each bird species as a disperser to the overall plant community (Bascompte, Jordano, \& Olesen 2006); (5) bird specialization d', which quantifies the species' selectiveness for resources (Blüthgen et al. 2006); and (6) number of plant species dispersed by each bird species (other than blackberry). In the simulations that allowed interaction rewiring, the blackberry was deleted from the interaction matrix and the observed frequency of these interactions was randomly assigned to other plant species dispersed by the remaining bird species in the network. To avoid the occurrence of forbidden links, we only allowed new pairwise interactions if they were previously detected in any of the 17 networks. Since the random redistribution of the interactions produces a different interaction matrix in each run, we repeated this process 100 times, after which the mean and 95\% bias-corrected and accelerated (BCa) bootstrapped confidence intervals (10,000 replicates) (Efron, 1987) were mostly constant regardless of the number of runs (see Appendix A: Figs. 1 and 2 in Supplementary material). In the extinction simulation without rewiring, the blackberry was deleted from the interaction matrix along with those bird species that only dispersed this species. This procedure resulted in a single matrix that was a reduced form of the full empirical network. The descriptors predicted by the extinction simulations, with and without rewiring, were then compared with those of the observed network after the experimental removal of blackberries.

Networks were visualized using specific code implemented in Mathematica 9.0 (Wolfram Research 2012), and all data analysis was performed in R (R Core Team 2017) using packages "RVAideMemoire" (Hervé, 2017) to compute G-tests, "bipartite" (Dormann, Gruber, \& Fründ 2008; Dormann, Fründ, Blüthgen, \& Gruber 2009) to compute 

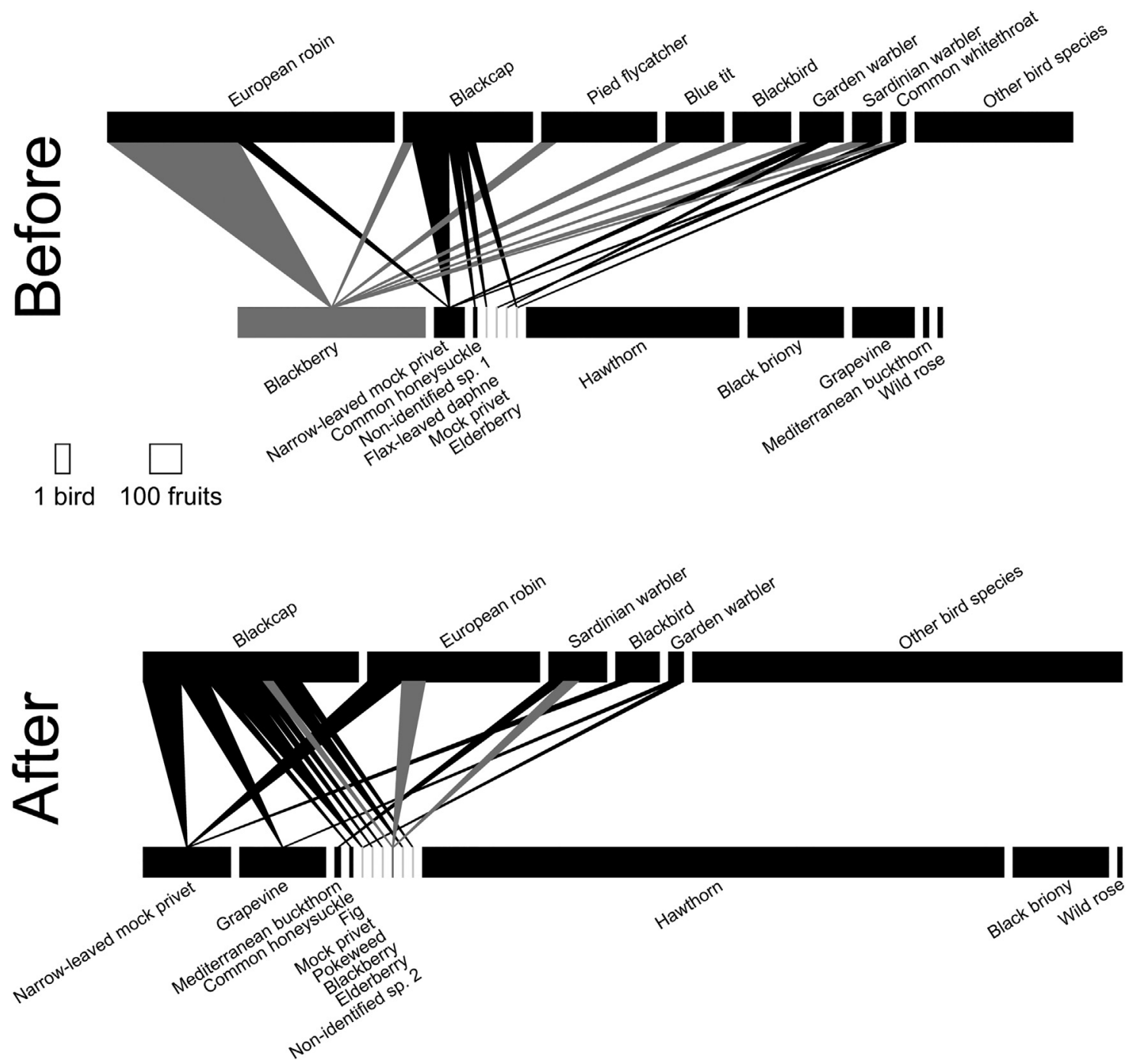

Fig. 2. Structure of the seed dispersal network before and after the experimental removal of blackberries. The upper and lower levels of each network, drawn to the same scale, represent bird and plant species, respectively, and the width of the links between the levels is proportional to the number of droppings of each bird species that contained intact seeds. The width of each bird's and plant's box depicts, respectively, the number of captured birds and the abundance of fruits in the transects. The bird boxes without any links include all captured bird species that did not disperse any seeds. Interactions with the blackberry (Rubus ulmifolius) are represented in dark grey; plants whose fruits were found in the transects are represented in black; and plant species with seeds found in the droppings but not in the transects are represented in light grey; robin (Erithacus rubecula), blackcap (Sylvia atricapilla), pied flycatcher (Ficedula hypoleuca), blue tit (Cyanistes caeruleus), blackbird (Turdus merula), garden warbler (Sylvia borin), Sardinian warbler (S. melanocephala), common whitethroat (S. communis), narrow-leaved mock privet (Phillyrea angustifolia), common honeysuckle (Lonicera periclymenum), flax-leaved daphne (Daphne gnidium), mock privet (P. latifolia), elderberry (Sambucus nigra), hawthorn (Crataegus monogyna), black briony (Tamus communis), grapevine (Vitis vinifera), Mediterranean buckthorn (Rhamnus alaternus), wild rose (Rosa sp.), fig (Ficus carica), pokeweed (Phytolacca americana).

network- and species-level descriptors, and "boot" (Canty \& Ripley 2014) to compute 95\% BCa bootstrapped confidence intervals.

\section{Results}

\section{Characterization of the seed dispersal networks}

Overall, we captured 2381 birds belonging to 64 species in the 17 sites, of which 587 birds from 24 species (Fig. 1) and
13 families dispersed 3974 seeds from 35 plant species. Of all bird species that dispersed seeds, two are partially migratory (i.e. those with both resident and migratory populations), namely the European robin (Erithacus rubecula, hereafter robin) and blackcap (Sylvia atricapilla), while 12 species are migratory. Each network included on average 7.4 ( \pm 2.9 S.D.) bird species and $6.2( \pm 2.7)$ plant species. The large majority $(80 \%, 28$ species) of all dispersed seed species were from fleshy fruits. Overall, five bird species - robin, pied flycatcher (Ficedula hypoleuca), blackcap, garden warbler (S. borin), and Sardinian warbler (S. melanocephala) - accounted for 


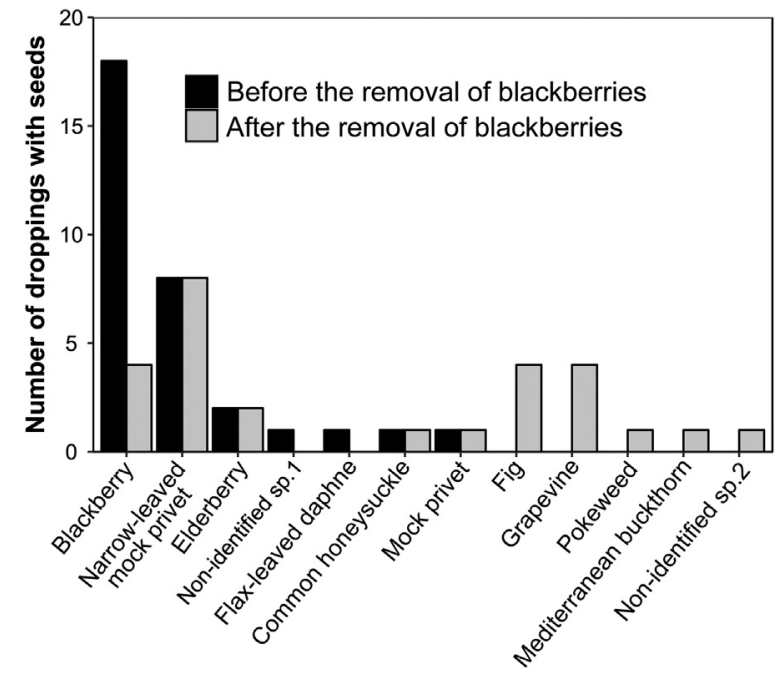

Fig. 3. Number of bird droppings with seeds (interaction frequency) of each plant species before and after the experimental removal of blackberries.

more than half of all pairwise interactions (55\%) and the vast majority of the droppings with seeds (76\%). The blackcap was the most important disperser species, being present on 14 sites, and dispersing on average $65 \%$ of the plants species at each site. Other relevant dispersers were the Sardinian warbler, garden warbler, European robin, and pied flycatcher, dispersing $45 \%, 38 \%, 37 \%$, and $24 \%$ of the plant species at each site, respectively. Blackberry seeds were present in 16 of the 17 networks and were the most commonly dispersed species in 13 of those sites (Fig. 1), being present in $43 \%$ of all droppings with seeds. These seeds were dispersed by 17 out of 24 disperser species, and by most disperser species at each site $($ mean $=73 \% \pm 30 \%)$.

\section{Experimental removal of the most dispersed plant species}

Before the experimental removal of blackberries, eight bird species dispersed seven species of plants, with all of them dispersing blackberry seeds (Fig. 2). Of all droppings with blackberry seeds, $56 \%$ were droppings from robin. Three bird species: blue tit (Cyanistes caeruleus), pied flycatcher, and blackbird (Turdus merula), dispersed only blackberry before the removal of its fruits (Fig. 2). Blackberry had the second highest standing fruit crop (31\% of all available fruits, only surpassed by hawthorn, which is only consumed later in the season), and was by far the most dispersed species at this site (56\% of all interactions) (Figs. 2 and 3).

There were no differences in the overall number of birds captured before and after the removal of blackberries (before vs. after $=62$ vs. 65 ; G-test $=0.035$, d.f. $=1, p=0.852$ ), in the total number of droppings collected ( 53 vs. 57 ; G-test $=0.071$, d.f. $=1, p=0.789)$, nor in the number of droppings with seeds ( 23 vs. 19 ; $\mathrm{G}$-test $=0.2$, d.f. $=1, \mathrm{p}=0.655$ ). As expected, the number of droppings with blackberry seeds declined signifi- cantly after the removal of its fruits ( $18 \mathrm{vs.} 4$; G-test $=6.223$, d.f. $=1, p=0.013$ ), whereas there was a considerable, yet nonsignificant increase in the number of droppings with other seed species ( 10 vs. 17; G-test $=0.789$, d.f. $=1, p=0.374$ ). The removal of blackberries did not lead to the dominance of any other plant species in the network (Figs. 2 and 3). Five plant species were dispersed only after the removal, most notably fig and grapevine, with four interactions each, but also the Mediterranean buckthorn (Rhamnus alaternus), pokeweed (Phytolacca americana), and an unidentified seed species (Fig. 3). The main blackberry disperser before its removal (robin) did not disperse any new plant species but increased the dispersal frequency of the previously dispersed species (narrow-leaved mock privet) present in 5\% and 25\% of the droppings of robins before and after the removal of blackberries, respectively (Fig. 2). Of the three bird species that dispersed only blackberries before its removal, two species (blue tit and pied flycatcher) did not disperse any seed while one (blackbird) started to disperse the narrow-leaved mock privet after the removal of blackberries (Fig. 2).

In general, extinction simulations with rewiring provided better predictions of the observed network topology than those without rewiring (Fig. 4). Both observed network specialization $\mathrm{H}_{2}{ }^{\prime}$ and weighted connectance were relatively well predicted by the simulations with rewiring (Fig. 4A and B). On the contrary, nestedness (weighted NODF) was underestimated, with both simulation scenarios rendering similar estimations (Fig. 4C).

Overall, both simulation scenarios provided poor predictions for the observed species-level descriptors (Fig. 5). Predicted species strength was highly inaccurate for most species, with simulations without rewiring performing slightly better than those with rewiring for three bird species (Fig. 5A). Specialization d' was accurately predicted for only two species: blackcap with rewiring and garden warbler without rewiring (Fig. 5B). Simulations without rewiring also performed better in the estimation of the number of dispersed seed species other than the blackberry, producing good estimates for three bird species (Fig. 5C).

\section{Discussion}

Here, we characterized avian seed dispersal during the peak of the fruiting season which coincides with the autumn bird migration through Portugal and show that blackberry, a native species, is by far the most important fruit resource across the country. The experimental removal of blackberries from one experimental site did not significantly affect bird community composition and induced a small increase on the dispersal of co-occurring fleshy-fruits. The changes at the community-level were better predicted by a simulation model that allowed interaction rewiring, although the disparate responses of each bird species to the removal of blackberries hampered the accurate prediction of specieslevel roles. 

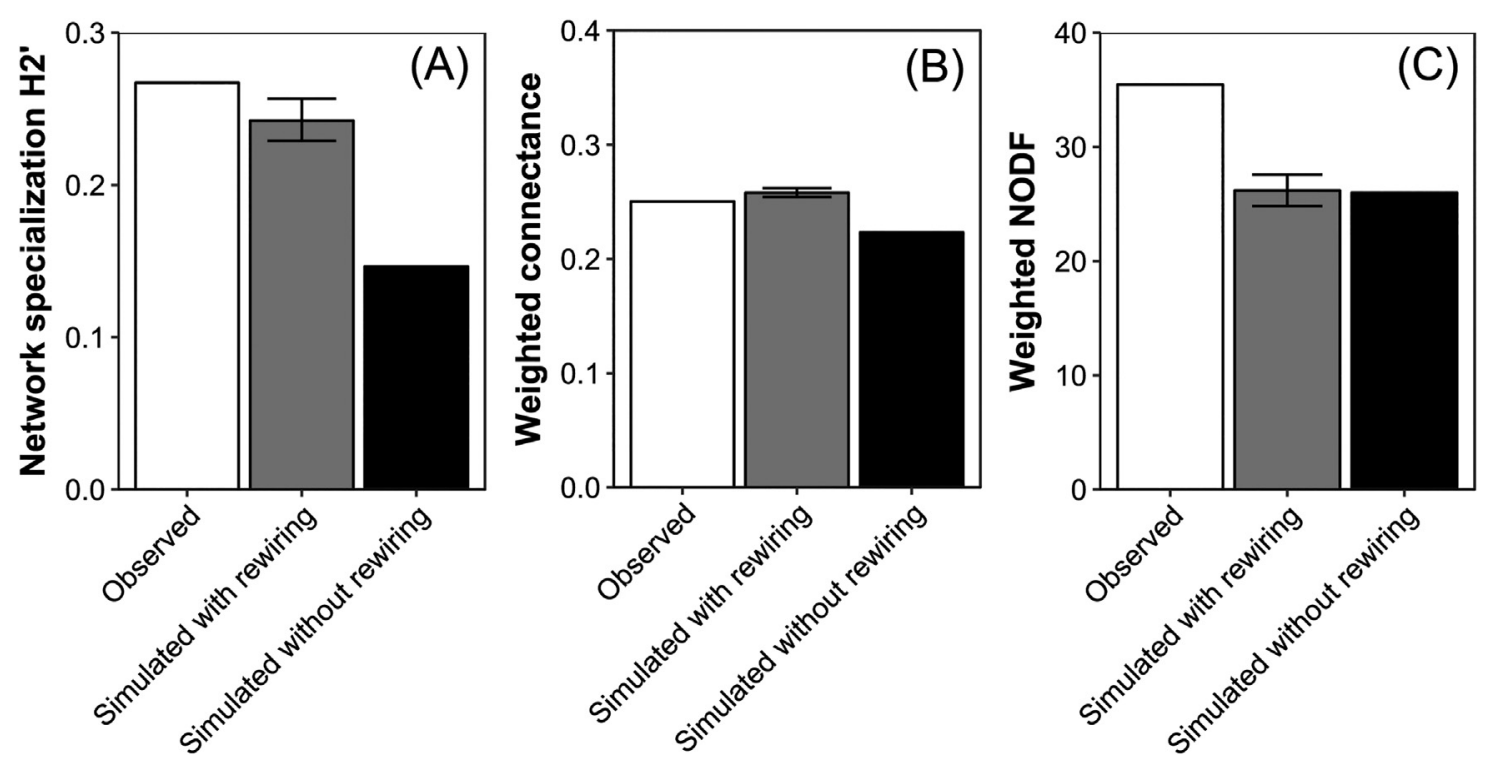

Fig. 4. Network-level descriptors of the observed network after the removal of blackberry fruits and of secondary extinction models with and without rewiring: (A) network specialization $\mathrm{H}_{2}{ }^{\prime}$, (B) weighted connectance, and (C) nestedness (weighted NODF). The figures corresponding to the simulation with rewiring depict the mean of 100 runs with the error bars indicating the $95 \%$ bias-corrected and accelerated (BCa) bootstraped confidence intervals of the simulations with rewiring.

\section{Characterization of the seed dispersal networks}

The vast majority of the interactions were performed by five bird species that were recorded in almost all sites, four of these are known for being among the most important seed dispersers in the Mediterranean region: robin, blackcap, and the garden and Sardinian warblers (Herrera 1995). We also detected a number of typically non-frugivorous bird species dispersing fleshy-fruited seeds (e.g. the insectivorous great spotted woodpecker Dendrocopos major and the granivorous chaffinch Fringilla coelebs) as well as granivorous species dispersing undamaged seeds from herbaceous plants (e.g. Spanish sparrow Passer hispaniolensis). These findings add up to those of other studies that have empirically demonstrated the existence of a continuum in the contribution of frugivorous and non-frugivorous birds to seed dispersal (Heleno, Ross, Everard, Memmott, \& Ramos 2011).

The 17 seed dispersal networks reported here clearly show that the blackberry is consistently the most important fruit resource for birds during the autumn migration across Portugal. The consumption and dispersal of its seeds by birds has been often documented (e.g. Jordano 1982, 1984; Debussche \& Isenmann 1989; Fuentes 1994), but the spatial consistency of its importance (sampling sites with a longitudinal distribution of more than $500 \mathrm{~km}$ across the Iberian Peninsula) was still unappreciated. Blackberry seeds were dispersed by a variety of bird species displaying a gradient of dependence on fruits, including typical frugivores, e.g. garden warbler, mainly granivores, e.g. rock bunting (Emberiza cia), and mostly insectivores, e.g. blue tit. Such importance may be partly explained by the composition of its fruits, rich in water and non-structural carbohydrates that are easily metabolized, making it a valuable water and energy source for many birds
(Jordano 1982; Herrera 1987). Additionally, its abundance and morphology, composed of small drupelets, make the fruits of blackberry a valuable resource for a variety of bird species.

\section{Experimental removal of the most dispersed plant species}

Five plant species were only dispersed after the removal of blackberries, chiefly the fig (Ficus carica) and the grapevine (Vitis vinifera). These plants were dispersed by blackcap, and the garden and Sardinian warblers, all of which dispersed blackberry seeds before their removal, suggesting rewiring towards these plant species. Contrary to our expectations, the main blackberry disperser in this site (robin) did not disperse any new plant species after the removal of its fruits but increased the dispersal frequency of other previously dispersed species. This result suggests that the proportion of the robin's diet previously filled by blackberries was slightly diverted to fruits of narrow-leaved mock privet. The robin is an omnivore species that includes a large fraction of invertebrates in its diet along with fleshy fruits (Debussche \& Isenmann 1985; Heleno, Ramos, \& Memmott 2013) and it did not leave the study site, so it probably compensated the loss of blackberries also by increasing the consumption of the previously consumed fruit species and probably also non-fruit resources. Similarly, all the other bird species found in this study are not exclusively frugivorous, they may also divert their foraging effort not only to other fruit species but also to non-fruit items, namely invertebrates. If this was the case, their functional role as seed dispersers may have been reduced even though bird population were largely unaffected by the 

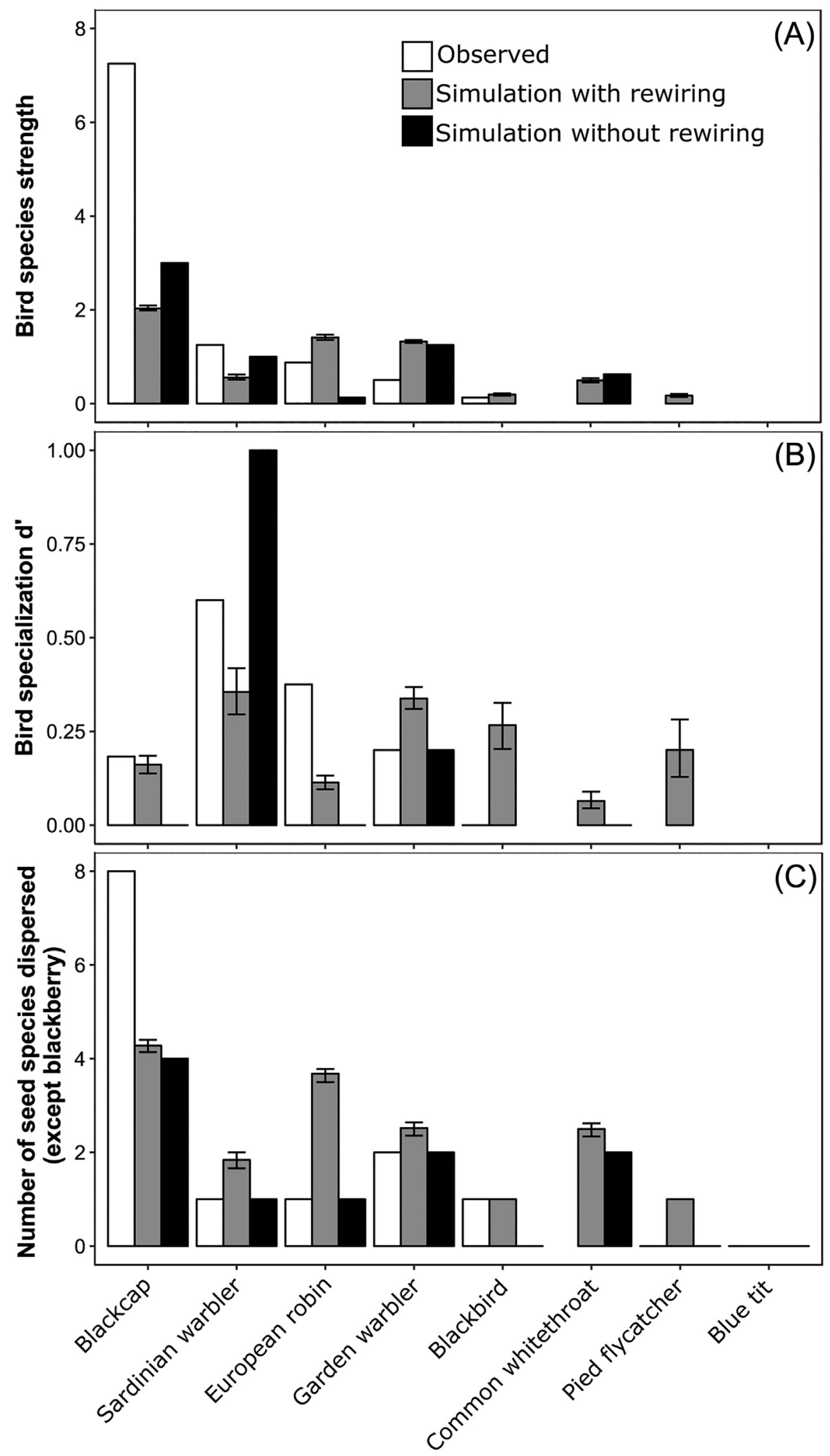

Fig. 5. Species-level descriptors of the observed interactions after the experimental removal of blackberry fruits and of secondary extinction models with and without rewiring: (A) bird specialization $\mathrm{d}^{\prime}$, (B) species strength, and (C) number of dispersed seed species, other than blackberry. Bird species are ordered according to their observed species strength. The figures corresponding to the simulation with rewiring depict the mean of 100 runs with the error bars indicating the $95 \%$ bias-corrected and accelerated (BCa) bootstraped confidence intervals of the simulations with rewiring. Missing bars correspond to missing data while those represented by a horizontal line correspond to observed values of zero. 
loss of an abundant fruit resource. Unfortunately, we did not quantify the non-fruit component of the bird diet in this study. Nevertheless, ignoring the ecological plasticity of omnivores is likely to undermine the predictions of secondary extinction models as they can supply their energetic demands by shifting into alternative sources (Blüthgen 2010; Schleuning et al. 2016; Timóteo et al. 2016).

Both specialization $\mathrm{H}_{2}{ }^{\prime}$ and weighted connectance after the removal of the blackberries were considerably better predicted by extinction simulation models that incorporate rewiring. Nestedness (weighted NODF), however, was highly underestimated by both types of models, only with a negligible improvement in models that allowed interaction rewiring. In ant-seed dispersal networks, other observed descriptors such as network robustness and seed species richness were largely underestimated by extinction simulations with rewiring (Timóteo et al. 2016). Extinction simulations without rewiring also failed to predict network specialization $\mathrm{H}_{2}{ }^{\prime}$ in a pollination study, where flowers had been manually removed (Goldstein \& Zych 2016). These results suggest that when accounting for rewiring, some network-level descriptors may be better predicted than others, while without rewiring, all network descriptors are poorly predicted.

Regarding the individual role of the species (i.e. specieslevel descriptors), simulations with and without rewiring performed similarly. Such poor performance is also a reflection of the difficulty in estimating specific feeding choices with simple algorithms and that more complex rewiring rules might be necessary for greater accuracy in estimating species roles after environmental disturbances (Olito \& Fox 2015; Trøjelsgaard \& Olesen 2016). The rearrangement of interactions after one species declined is intrinsically difficult to predict since it requires more data than just the presence of a potential partner species. An important limitation of current rewiring protocols is that they often only redistribute the lost interactions through resources that were already known to be consumed locally, not allowing the establishment of new interactions (Rumeu et al. 2017). Here we constrained rewiring to any of the pairwise interactions that had been observed in any of the 17 networks sampled across the country. Such an extensive background pool of potential interactions is an improvement over models that simply redistribute the lost interactions across the local resources without accounting for the identity of potential interacting partners. However, at the experimental site after the removal of blackberries, we recorded interactions that, despite being observed at any of the 17 sites, were not considered in rewiring simulations because those plant species were not observed at that site. Accordingly, we observed new, previously unrecorded plant species being dispersed after the experimental treatment by some important disperser species (e.g. blackcap), while others (e.g. robin) exhibited a lower plasticity than expected by not dispersing any new plant species. This constraint may have hindered more accurate predictions of bird species roles after the removal of blackberries, and highlight the need of an exhaustive list of all local available plant species. Factors that are also known to shape bird-fruit interactions and ultimately rewiring dynamics include availability of alternative food resources, inter-specific competition, both bird and plant species abundances, bird preferences for some fruit species over others due to characteristics such as fruit nutritional content, and also temporal, spatial, and morphological trait matching (Martin 1985; Levey \& Martínez del Rio 2001; Burns 2006; Jordano 2014, 2016). Moreover, these factors may vary across space (Poisot et al. 2014), such as the intra-specific variability in fruit size or bird gape width, constraining potential interactions across the landscape (González-Varo \& Traveset 2016). The incorporation of all these interaction drivers, e.g. by the inclusion of more refined rewiring probabilities based on species traits or abundances (Ramos-Jiliberto et al. 2012), hold a great potential to improve the realism of rewiring simulations, and particularly to predict species topological roles after disturbances (Stang, Klinkhamer, \& Meijden 2006; Santamaría \& RodríguezGironés 2007; Kaiser-Bunbury, Vázquez Diego, Stang, \& Ghazoul 2014).

The second part of our study (manipulative experiment) was limited to one site due to the logistical constraints of the experiment, namely to accumulate sufficient sampling hours with enough mist-nets and to remove all blackberries within $100 \mathrm{~m}$ from the nets. A two-week sampling period was chosen to optimize the trade-off in data quality regarding the effort to satisfactorily sample the network to overcome potential differences caused by the advance of plant fruiting phenology and bird migration. Despite the short sampling period, we are confident that the two networks (before and after) reliably show the effect of the removal of blackberries. A similar constraint occurred in the first part of our study, where a sampling effort of five days, which was selected based on a previous study in this system showing that five days was enough to record most species of birds and dispersed seeds (Costa et al. 2016), might have missed some rare interactions, such as those with abundant fleshy fruits that were not dispersed at any site (blackthorn Prunus spinosa, hawthorn, prickly juniper Juniperus oxycedrus, and Rosa spp.). However, these fruits are hardly consumed until the end of the fruiting season, making them unimportant resources in early September (when sampling took place) for frugivorous birds. Nevertheless, our sampling allowed the detection of several rare interactions involving non-frugivorous bird species and small dry fruits.

Although similar studies are still scarce, there is an emerging consensus that accounting for interaction rewiring increases the accuracy of species extinction simulations. Recent evidence shows that network architecture can respond very differently depending on the identity and abundance of the extinct and remaining species (Rumeu et al. 2017). Network descriptors are known to be relatively stable to species turnover (Petanidou et al. 2008), rendering networklevel descriptors easier to estimate with simple rewiring rules. Nevertheless, studies where alien species were experimentally removed showed different levels of plasticity at 
the level of network structure (Heleno, Lacerda, Ramos, \& Memmott 2010; Ferrero et al. 2013; Goldstein \& Zych 2016; Kaiser-Bunbury et al. 2017). Therefore, detailed knowledge of each study system is likely invaluable for accurate predictions regarding community responses to local extinctions. To date, the few studies that experimentally evaluated community rearrangement are limited to the removal of a single species (Heleno et al. 2010; Brosi and Briggs 2013; Goldstein \& Zych 2016; Timóteo et al. 2016; Hallett et al. 2017, this study). Collectively, these studies show that rewiring occurs when a highly connected species goes extinct, but also that rewiring patterns are hard to model, and this difficulty is likely to increase greatly when simulating the consequences of multiple species extinctions.

\section{Acknowledgements}

We thank the Portuguese ringing authority (CEMPA/ICNF) for providing us with the bird rings and ringing permits, and all the observers that contributed to the data collection. We are also thankful to Jane Memmott for sharing specific code, and to Christopher Kaiser Bunbury and two anonymous reviewers whose comments greatly improved the manuscript. J.M.C., L.P.S., P.M.A., E.C., R.J.L., A.C.N. and R.H. were supported by Fundação para Ciência e Tecnologia, and POPH/QREN/FSE grants: SFRH/BD/96292/2013, SFRH/BD/77746/2011, $\mathrm{PD} / \mathrm{BD} / 52594 / 2014$, SFRH/BD/69238/2010, SFRH/BPD/84141/2012, SFRH/BPD/62898/2009, and IF/00441/2013, respectively. R.H. was also supported by the Marie Curie action FP7-PEOPLE-2012-CIG321794. This work was financed by FCT/MEC through national funds and co-funded by FEDER, within the PT2020 Partnership Agreement, and COMPETE 2020, within projects UID/BIA/04004/2013 and UID/MAR/04292/2013.

\section{Appendix A. Supplementary data}

Supplementary data associated with this article can be found, in the online version, at https://doi.org/10.1016/ j.baae.2018.05.011.

\section{References}

Almeida-Neto, M., \& Ulrich, W. (2011). A straightforward computational approach for measuring nestedness using quantitative matrices. Environmental Modelling \& Software, 26, 173-178.

Bascompte, J., Jordano, P., \& Olesen, J. M. (2006). Asymmetric coevolutionary networks facilitate biodiversity maintenance. Science, 312, 431-433.

Bello, C., Galetti, M., Pizo, M. A., Magnago, L. F. S., Rocha, M. F., Lima, R. A. F., et al. (2015). Defaunation affects carbon storage in tropical forests. Science Advances, 1
Bersier, L.-F., Banasek-Richter, C., \& Cattin, M.-F. (2002). Quantitative descriptors of food-web matrices. Ecology, 83, 2394-2407.

Blüthgen, N. (2010). Why network analysis is often disconnected from community ecology: A critique and an ecologist's guide. Basic and Applied Ecology, 11, 185-195.

Blüthgen, N., Menzel, F., \& Blüthgen, N. (2006). Measuring specialization in species interaction networks. BCM Ecology, 6, 9.

Blüthgen, N., Menzel, F., Hovestadt, T., Fiala, B., \& Blüthgen, N. (2007). Specialization, constraints, and conflicting interests in mutualistic networks. Current Biology, 17, 341-346.

Bond, W. J. (1994). Do mutualisms matter? Assessing the impact of pollinator and disperser disruption on plant extinction. Philosophical Transactions of the Royal Society of London. Series B: Biological Sciences, 344, 83-90.

Brodie, J. F., Aslan, C. E., Rogers, H. S., Redford, K. H., Maron, J. L., Bronstein, J. L., et al. (2014). Secondary extinctions of biodiversity. Trends in Ecology \& Evolution, 29, 664-672.

Brosi, B. J., \& Briggs, H. M. (2013). Single pollinator species losses reduce floral fidelity and plant reproductive function. Proceedings of the National Academy of Sciences United States of America, 110, 13044-13048.

Burns, K. C. (2006). A simple null model predicts fruit-frugivore interactions in a temperate rainforest. Oikos, 115, 427-432.

Canty, A., \& Ripley, B. (2014). boot: Bootstrap R (S-Plus) Functions. R package version 1.3-13.

CaraDonna, P. J., Petry, W. K., Brennan, R. M., Cunningham, J. L., Bronstein, J. L., Waser, N. M., et al. (2017). Interaction rewiring and the rapid turnover of plant-pollinator networks. Ecology Letters, 20, 385-394.

Carvalheiro, L. G., Barbosa, E. R. M., \& Memmott, J. (2008). Pollinator networks, alien species and the conservation of rare plants: Trinia glauca as a case study. Journal of Applied Ecology, 45, 1419-1427.

Correa, S. B., Arujo, J. K., Penha, J., Nunes da Cunha, C., Bobier, K. E., \& Anderson, J. T. (2016). Stability and generalization in seed dispersal networks: A case study of frugivorous fish in Neotropical wetlands. Proceedings of the Royal Society B: Biological Sciences, 283, 20161267.

Correia, M., Timóteo, S., Rodríguez-Echeverría, S., Mazars-Simon, A., \& Heleno, R. (2016). Refaunation and the reinstatement of the seed-dispersal function in Gorongosa National Park. Conservation Biology, 31, 76-85.

Costa, J. M., da Silva, L. P., Ramos, J. A., \& Heleno, R. H. (2016). Sampling completeness in seed dispersal networks: When enough is enough. Basic and Applied Ecology, 17, 155-164.

Debussche, M., \& Isenmann, P. (1985). Frugivory of transient and wintering European robins Erithacus rubecula in a Mediterranean region and its relationship with ornithochory. Holarctic Ecology, 8, 157-163.

Debussche, M., \& Isenmann, P. (1989). Fleshy fruit characters and the choices of bird and mammal seed dispersers in a Mediterranean region. Oikos, 56, 327-338.

Dormann, C. F., Fründ, J., Blüthgen, N., \& Gruber, B. (2009). Indices, graphs and null models: Analyzing bipartite ecological networks. The Open Ecology Journal, 2, 7-24. 
Dormann, C. F., Gruber, B., \& Fründ, J. (2008). Introducing the bipartite package: Analysing ecological networks. R News, 8, 8-11.

Efron, B. (1987). Better bootstrap confidence intervals. Journal of the American Statistical Association, 82, 171-185.

Farwig, N., \& Berens, D. G. (2012). Imagine a world without seed dispersers: A review of threats, consequences and future directions. Basic and Applied Ecology, 13, 109-115.

Ferrero, V., Castro, S., Costa, J., Acuña, P., Navarro, L., \& Loureiro, J. (2013). Effect of invader removal: Pollinators stay but some native plants miss their new friend. Biological Invasions, 15, 2347-2358.

Fründ, J., McCann, K. S., \& Williams, N. M. (2016). Sampling bias is a challenge for quantifying specialization and network structure: lessons from a quantitative niche model. Oikos, 125, 502-513.

Fuentes, M. (1994). Diets of fruit-eating birds: What are the causes of interspecific differences? Oecologia, 97, 134-142.

Fuentes, M. (1995). How specialized are fruit-bird interactions? Overlap of frugivore assemblages within and between plant species. Oikos, 74, 324-330.

Goldstein, J., \& Zych, M. (2016). What if we lose a hub? Experimental testing of pollination network resilience to removal of keystone floral resources. Arthropod-Plant Interactions, 10, 263-271.

González-Varo, J. P., \& Traveset, A. (2016). The labile limits of forbidden interactions. Trends in Ecology \& Evolution, 31, 700-710

Hallett, A. C., Mitchell, R. J., Chamberlain, E. R., \& Karron, J. D. (2017). Pollination success following loss of a frequent pollinator: The role of compensatory visitation by other effective pollinators. AoB Plants, 9, plx020.

Heleno, R., Lacerda, I., Ramos, J. A., \& Memmott, J. (2010). Evaluation of restoration effectiveness: Community response to the removal of alien plants. Ecological Applications, 20, 1191-1203.

Heleno, R. H., Olesen, J. M., Nogales, M., Vargas, P., \& Traveset, A. (2013). Seed dispersal networks in the Galápagos and the consequences of alien plant invasions. Proceedings of the Royal Society B: Biological Sciences, 280.

Heleno, R. H., Ramos, J. A., \& Memmott, J. (2013). Integration of exotic seeds into an Azorean seed dispersal network. Biological Invasions, 15, 1143-1154.

Heleno, R. H., Ross, G., Everard, A., Memmott, J., \& Ramos, J. A. (2011). The role of avian 'seed predators' as seed dispersers. Ibis, 153, 199-203.

Herrera, C. M. (1987). Vertebrate-dispersed plants of the Iberian Peninsula: A study of fruit characteristics. Ecological Monographs, 57, 305-331.

Herrera, C. M. (1995). Plant-vertebrate seed dispersal systems in the Mediterranean: Ecological, evolutionary, and historical determinants. Annual Review of Ecology, Evolution, and Systematics, 26, $705-727$.

Hervé, M. (2017). RVAideMemoire: Testing and plotting procedures for biostatistics. $R$ package version 0.9-68.

Isbell, F., Gonzalez, A., Loreau, M., Cowles, J., Díaz, S., Hector, A., et al. (2017). Linking the influence and dependence of people on biodiversity across scales. Nature, 546, 65 .

Ives, A. R., \& Cardinale, B. J. (2004). Food-web interactions govern the resistance of communities after non-random extinctions. Nature, 429, 174.
Jordano, P. (1982). Migrant birds are the main seed dispersers of blackberries in southern Spain. Oikos, 38, 183-193.

Jordano, P. (1984). Seed weight variation and differential avian dispersal in blackberries Rubus ulmifolius. Oikos, 43, 149-153.

Jordano, P. (2014). Fruits and frugivory. In R. S. Gallagher (Ed.), Seeds: The ecology of regeneration in plant communities (pp. 18-61). Wallingford, U.K: CABI.

Jordano, P. (2016). Sampling networks of ecological interactions. Functional Ecology, 30, 1883-1893.

Kaiser-Bunbury, C. N., Vázquez Diego, P., Stang, M., \& Ghazoul, J. (2014). Determinants of the microstructure of plant-pollinator networks. Ecology, 95, 3314-3324.

Kaiser-Bunbury, C. N., Mougal, J., Whittington, A. E., Valentin, T., Gabriel, R., Olesen, J. M., et al. (2017). Ecosystem restoration strengthens pollination network resilience and function. Nature, 542, 223-227.

Kaiser-Bunbury, C. N., Muff, S., Memmott, J., Müller, C. B., \& Caflisch, A. (2010). The robustness of pollination networks to the loss of species and interactions: A quantitative approach incorporating pollinator behaviour. Ecology Letters, 13, 442-452.

Levey, D. J., \& Martínez del Rio, C. (2001). It takes guts (and more) to eat fruit: Lessons from avian nutritional ecology. Auk, 118, 819-831.

Martin, T. E. (1985). Resource selection by tropical frugivorous birds: Integrating multiple interactions. Oecologia, 66, 563-573.

Memmott, J., Waser, N. M., \& Price, M. V. (2004). Tolerance of pollination networks to species extinctions. Proceedings of the Royal Society of London. Series B, 271, 2605-2611.

Olesen, J. M., Bascompte, J., Dupont, Y. L., Elberling, H., Rasmussen, C., \& Jordano, P. (2011). Missing and forbidden links in mutualistic networks. Proceedings of the Royal Society B: Biological Sciences, 278, 725-732.

Olito, C., \& Fox, J. W. (2015). Species traits and abundances predict metrics of plant-pollinator network structure, but not pairwise interactions. Oikos, 124, 428-436.

Petanidou, T., Kallimanis, A. S., Tzanopoulos, J., Sgardelis, S. P., \& Pantis, J. D. (2008). Long-term observation of a pollination network: Fluctuation in species and interactions, relative invariance of network structure and implications for estimates of specialization. Ecology Letters, 11, 564-575.

Plein, M., Morris, W. K., Moir, M. L., \& Vesk, P. A. (2017). Identifying species at coextinction risk when detection is imperfect: Model evaluation and case study. PLoS One, 12, e0183351.

Poisot, T., Stouffer, D. B., \& Gravel, D. (2014). Beyond species: Why ecological interaction networks vary through space and time. Oikos, 124, 243-251.

R Core Team. (2017). $R$ : A language and environment for statistical computing. Vienna, Austria: R Foundation for Statistical Computing. http://www.R-project.org/

Ramos-Jiliberto, R., Valdovinos, F. S., Moisset de Espanés, P., \& Flores, J. D. (2012). Topological plasticity increases robustness of mutualistic networks. Journal of Animal Ecology, 81, 896-904.

Rumeu, B., Devoto, M., Traveset, A., Olesen, J. M., Vargas, P., Nogales, M., et al. (2017). Predicting the consequences of disperser extinction: Richness matters the most when abundance is low. Functional Ecology, 31, 1910-1920. 
Santamaría, L., \& Rodríguez-Gironés, M. A. (2007). Linkage rules for plant-pollinator networks: Trait complementarity or exploitation barriers? PLoS Biology, 5, e31.

Santamaría, S., Galeano, J., Pastor, J. M., \& Méndez, M. (2014). Robustness of alpine pollination networks: Effects of network structure and consequences for endemic plants. Arctic, Antarctic, and Alpine Research, 46, 568-580.

Schleuning, M., Fründ, J., Schweiger, O., Welk, E., Albrecht, J., Albrecht, M., et al. (2016). Ecological networks are more sensitive to plant than to animal extinction under climate change. Nature Communications, 7, 13965.

Stang, M., Klinkhamer, P. G. L., \& Meijden, E. v. d. (2006). Size constraints and flower abundance determine the number of interactions in a plant-flower visitor web. Oikos, 112, $111-121$.

Thébault, E., \& Fontaine, C. (2010). Stability of ecological communities and the architecture of mutualistic and trophic networks. Science, 329, 853-856.

Timóteo, S., Ramos, J. A., Vaughan, I. P., \& Memmott, J. (2016). High resilience of seed dispersal webs highlighted by the exper- imental removal of the dominant disperser. Current Biology, 26, 910-915.

Traveset, A., Heleno, R. H., \& Nogales, M. (2014). The ecology of seed dispersal. In R. S. Gallagher (Ed.), Seeds: The ecology of regeneration in plant communities (pp. 62-93). Wallingford: CABI.

Trøjelsgaard, K., Jordano, P., Carstensen, D. W., \& Olesen, J. M. (2015). Geographical variation in mutualistic networks: Similarity, turnover and partner fidelity. Proceedings of the Royal Society B: Biological Sciences, 282, 20142925.

Trøjelsgaard, K., \& Olesen, J. M. (2016). Ecological networks in motion: Micro- and macroscopic variability across scales. Functional Ecology, 30, 1926-1935.

Vázquez, D. P., Morris, W. F., \& Jordano, P. (2005). Interaction frequency as a surrogate for the total effect of animal mutualists on plants. Ecology Letters, 8, 1088-1094.

Vieira, M. C., \& Almeida-Neto, M. (2015). A simple stochastic model for complex coextinctions in mutualistic networks: Robustness decreases with connectance. Ecology Letters, 18, 144-152.

Wolfram Research, I. (2012). Mathematica, Version 9.0, Champaign, IL.

Available online at www.sciencedirect.com 